Short Communication

\title{
Worm-like Hierarchical Porous Carbon Derived from Bio- renewable Lignin with High $\mathrm{CO}_{2}$ Capture Capacity
}

\author{
Binglong Zhu, Jizhong Huang, Jingrong Lu, Dejian Zhao, Li Lu, Sijia Jin, Quanfa Zhou* \\ Jiangsu key laboratory of E-waste Recycling, School of Chemistry and Environmental Engineering, \\ Jiangsu University of Technology, Changzhou, 213001, China \\ *E-mail: labzqf@jsut.edu.cn
}

doi: $10.20964 / 2017.12 .49$

Received: 1 September 2017 / Accepted: 28 September 2017 / Published: 12 November 2017

The worm-like hierarchical pore structure carbon material was successfully prepared by a pyrolysis process. Bio-renewable lignin was introduced as the industrially available precursor. The hierarchical porous property and worm-like channel were characterized by nitrogen adsorption-desorption isotherms and TEM. Characterization results indicated that the carbon materials exhibited microporous and mesoporous structures with worm-like frameworks. $\mathrm{CO}_{2}$ capture tests approved that the worm-like hierarchical porous carbon showed excellent adsorption capacity of $26.2 \mathrm{mg} / \mathrm{g}$. In addition, the wormlike porous carbon shows a lower impedance.

Keywords: Carbon materials; Microstructure; Worm-like channel; $\mathrm{CO}_{2}$ capture;

\section{$\underline{\text { FULL TEXT }}$}

(C) 2017 The Authors. Published by ESG (www.electrochemsci.org). This article is an open access article distributed under the terms and conditions of the Creative Commons Attribution license (http://creativecommons.org/licenses/by/4.0/). 